\title{
DESENVOLVIMENTO MORAL DE UMA CRIANÇA CONSIDERADA "DIFÍCIL": FOCO NA RELAÇÃO ESCOLA-FAMÍLIA
}

\author{
Sandra Cristina Trambaiolli DE NADAI ${ }^{1}$ \\ Vanessa Fagionatto VICENTIN ${ }^{2}$ \\ Thais Leite BOZZA $^{3}$
}

RESUMO: A partir do relato de um caso vivenciado na escola, objetivou-se compreender e analisar as intervenções realizadas pela escola, no desenvolvimento moral de uma criança considerada "difícil", especificamente na relação entre a escola e a família. A partir da análise realizada desse caso, concluiu-se que a criança convive em um ambiente escolar autocrático, onde não há reflexão sobre as regras, não se permite a expressão dos sentimentos dos alunos e utiliza sanções expiatórias como formas de educação. Conclui-se também que existe uma dificuldade de se estabelecer uma parceria entre as instituições formadoras, visto que há terceirização das resoluções dos conflitos da escola para a família.

PALAVRAS-CHAVE: Conflitos interpessoais. Desenvolvimento moral. Parceria escola-família.

\section{Introdução}

Os conflitos interpessoais fazem parte das relações humanas, a forma como são concebidos pelos educadores, pode favorecer ou não o desenvolvimento moral dos alunos. Nas escolas, eles são frequentes; pesquisas apontam a angústia dos professores em lidar com essas situações em decorrência do fato de serem resolvidos de maneira pouco pacífica e respeitosa.

De acordo com uma pesquisa realizada pela Organização para a Cooperação e Desenvolvimento Humano - OCDH (BBC, 2014), 12,5\% dos professores, ouvidos no Brasil, disseram serem vítimas de agressões verbais ou de intimidação de alunos, pelo menos, uma vez por semana. Trata-se do índice mais alto entre os 34 países

\footnotetext{
${ }^{1}$ Psicóloga e psicopedagoga. PUCCAMP - Pontifícia Universidade Católica de Campinas. Especialista em relações interpessoais na escola pela UNIFRAN. Membro do GEPEM - Grupo de Estudos e Pesquisa em Educação moral (UNICAMP/UNESP). Campinas - SP - Brasil. 13086-900 - sctnadai@ hotmail.com. ${ }^{2}$ Psicóloga. PUCCAMP - Pontifícia Universidade Católica de Campinas. Mestrado. PUCCAMP Pontifícia Universidade Católica de Campinas. Doutora em Psicologia na área de Psicologia Escolar e do Desenvolvimento Humano. USP - Universidade de São Paulo. Membro do GEPEM - Grupo de Estudos e Pesquisa em Educação mora. Campinas - SP - Brasil. 13086-900 - vanessavicentin9@gmail.com.

${ }^{3}$ Pedagoga e mestranda em Educação. UNICAMP - Universidade Estadual de Campinas. Membro e monitora do GEPEM - Grupo de Estudos e Pesquisas em Educação Moral (UNESP/UNICAMP). Campinas - SP - Brasil. 13086-900 - thaisbozza@ hotmail.com.
} 
pesquisados - a média entre eles é de 3,4\%. Depois do Brasil, vem a Estônia, com 11\%, e a Austrália com 9,7\%.

Outra pesquisa, realizada pelo instituto Data Popular em parceria com a Apeoesp - Sindicato dos Professores do Ensino Oficial do Estado de São Paulo (SÃO PAULO, 2013), após ouvir 1400 professores, no primeiro semestre de 2013, aponta que dois em cada dez alunos da rede pública paulista admitem já terem cometido algum tipo de violência nas escolas. Apesar disso, a pesquisa revelou que $40 \%$ dos docentes afirmaram que suas escolas não realizam atualmente nenhuma campanha contra a violência, além disso, as que apresentam o maior índice de violência são as que menos realizam atividades voltadas para o problema.

O presente trabalho não tem a ambição de oferecer soluções que resolvam as questões dos conflitos na instituição escolar, mas a possibilidade de uma reflexão sobre as intervenções frente aos mesmos e suas consequências para o desenvolvimento moral da criança, em especial, da criança considerada “difícil”. Utilizou-se, como embasamento, a teoria construtivista piagetiana, focando a importância do ambiente sociomoral cooperativo que é baseado na cooperação, no respeito mútuo e na reciprocidade estabelecida entre os integrantes da comunidade escolar (DEVRIES; ZAN, 1995; ARAÚJO, 2001).

Dentro de um ambiente sociomoral cooperativo, as relações são pautadas no respeito mútuo, contribuindo para o desenvolvimento da autonomia moral, ou seja, o sujeito autônomo respeita regras por princípios internos e não porque são determinadas por uma autoridade. Já em escolas autocráticas, que fazem uso de coerções, ameaças e castigos, reforçando, assim, a moral heterônoma, a regulação é externa e está associada à autoridade.

Inúmeros estudos indicam que as escolas influenciam de modo significativo a formação moral das crianças, quer queiram ou não, e diante disso coloca-se a seguinte questão: em que medida as intervenções realizadas pela escola, na resolução de conflitos, favorece a construção da autonomia moral de uma criança considerada difícil?

A análise deste artigo foi realizada a partir de um relato de caso verídico com alguns pontos hipotéticos, procurando contemplar situações desafiadoras vivenciadas no cotidiano escolar.

Diante disso, tem-se como objetivo compreender e analisar as intervenções realizadas pela escola para o desenvolvimento moral de uma criança considerada “difícil”, especificamente, na relação entre escola-família. 
Os conflitos fazem parte das relações humanas, mas, geralmente, estão associados a uma situação indesejável. Contudo, em escolas, cuja concepção é democrática, os conflitos estarão mais presentes, porém, serão vistos como naturais e como oportunidades para a construção da autonomia moral. Para que essa autonomia seja oportunizada, são necessários procedimentos, tais como: o uso da linguagem descritiva, que favorece a relação de confiança e permite a reflexão dos atos e possíveis reparações (FABER; MAZLISH, 1985; GINOTT, 1972); e a sanção por reciprocidade, que, como diria Piaget $(1932,1994$, p.161), “[...] vão a par com a cooperação e as regras de igualdade".

Quando ocorrem conflitos na escola, geralmente, nos deparamos com a terceirização da resolução dos mesmos, ou seja, a escola julga que cabe à família a intervenção aos conflitos, mesmo que estes tenham ocorrido dentro da escola. Autores como Rego (1996), Vinha e Assis (2005), Silveira e Wagner (2009), Dedeschi e Licciardi (2012) apontam que as duas instituições educativas - família e escola - são responsáveis pelo desenvolvimento da criança e as práticas educacionais destas têm consequências para a construção da autonomia moral.

Buscando maior compreensão acerca das intervenções realizadas pela escola e procurando possibilidades de outras frente às situações de conflitos, com base na teoria construtivista, pretendemos auxiliar os educadores a refletirem e a perceberem a sua importância e de sua prática na formação da criança.

\section{Relato de caso}

\section{$\underline{\text { André }-8 \text { anos }}$}

Durante a aula de um segundo ano do ensino fundamental, de uma escola pública do interior paulista, a professora propõe a seguinte atividade:

Professora: Hoje, trabalharemos datas comemorativas, falaremos sobre a páscoa, como iremos montar um painel no pátio da escola, já trouxe um modelo pronto, de forma que todos os desenhos fiquem bem bonitos, sem sair do padrão, iremos pintar e depois recortar os desenhos.

André, um dos alunos da turma, contraria a professora e pinta o desenho com as cores da bandeira do Brasil: verde, amarelo, azul e branco. Um colega, Gustavo, que está ao lado de André conta para a professora: 
Gustavo: Professora, veja o desenho do André, acho que o coelho comeu a bandeira do Brasil, nunca vi coelho com essas cores rsrsrsrsrs...

André empurra Gustavo e parte para cima, a professora intervém, separa os meninos um para cada lado e diz:

Professora: Parem já com isso, só podia ser você mesmo, hein! Eu mandei usar as cores do modelo, você está sempre contrariando.

Os dois voltam para seu lugar e continuam fazendo a atividade.

André informa à professora que esqueceu sua tesoura com seu irmão gêmeo, na outra sala, e pede para buscá-la, a professora diz:

Professora: André, você não vai buscar nada agora, a regra da escola é que ninguém pode pegar material em outras salas, e regra é regra, tem que ser cumprida, estou falando e não me interrompa. Depois você não entende, faz feio, aí chora e fica bravinho e emburrado em sua carteira.

Depois de terminar sua explicação, a professora vai até a carteira de André e conversa com ele, dizendo que ela emprestaria uma tesoura, mas o aluno não aceita os argumentos da professora e começa a empurrar as carteiras dentro da sala, pega o lixo e joga na cabeça de um colega e sai correndo para a sala do irmão para pegar sua tesoura.

Nesse momento, a Coordenadora Pedagógica e a inspetora de aluno já ouviram os gritos e, ao verem André correndo para a outra sala, ficam na frente da porta, não permitindo sua entrada. Conversam, pedindo que ele volte para sua sala e afirmando que dariam outra tesoura, mas que não iria entrar na sala do irmão. Diante disso, André começa a gritar, dizendo que vai entrar de qualquer jeito e empurrando com força uma mesa, que está ao lado da porta, até o bebedouro e a quebra.

A Coordenadora foi segurá-lo, ele saiu correndo e, no meio do caminho, encontrou outra mesa, a qual empurrou até a parede e também quebrou. Continuou correndo pela escola e desafiando a todos com uma pedra na mão e dizia que se alguém se aproximasse, ele jogaria.

Diante disso, a família foi chamada para buscar a criança, sendo que esta sempre comparece quando a escola solicita. A escola considera que o comportamento do aluno tem relação com os problemas familiares. 
Quando a mãe chegou à escola, disse para a professora, diretora e coordenadora que o filho é perseguido pela escola e que não vê motivos para tanta confusão, que tudo que acontece na escola é culpa de seu filho, vou levá-lo embora e começou a gritar com a criança dizendo que iria tirar seu tablet por um mês e ficaria sem TV pelo mesmo tempo, que já não aguenta mais e queria ver o que aconteceria se a escola o expulsasse.

A diretora disse que a mãe fazia muito bem em deixá-lo de castigo e tirar o que ele gostava, porque do jeito que estava não poderia ficar e a escola já estava fazendo a sua parte. Além disso, diz a mãe que, toda a vez que acontecer algo com o André, a família será chamada para vir buscá-lo e se o comportamento não melhorar a escola irá reduzir seu tempo de permanência nas aulas, até se comportar decentemente.

A mãe levou o filho embora.

A professora, ao voltar para a sala, pediu silêncio aos alunos, disse que o problema já tinha sido resolvido e continuaram a atividade.

No outro dia, André retorna a escola e assina uma advertência por ter quebrado a mobília, ter desrespeitado a professora e agredido um colega.

\section{Revisão da literatura}

Os conflitos são inevitáveis nas relações interpessoais. Em contrapartida, no âmbito educacional, a frequência e as consequências de desacordos interpessoais - com sinais de violência em muitos casos - inquietam os integrantes da comunidade escolar. Diante disso, educadores demonstram sentimentos de impotência e insegurança ao lidar com os mesmos de maneira a favorecer a construção da autonomia, ou seja, a capacidade de governar a si próprio. Lembrando Piaget (1932, 1994, p.300) a "autonomia resulta da aceitação das regras de reciprocidade" o que parece difícil em alguns casos. Lidar com os conflitos tem sido tarefa angustiante, sentimento que se intensifica quando nos deparamos com situações de conflitos envolvendo crianças "difíceis", sendo compreendidas, nesse trabalho, como crianças com comportamentos agressivos, movidos pela raiva, um estado de mobilização emocional em que a criança apresenta crises de explosão, atacando as pessoas que estão a sua volta ou destruindo objetos (TRAIN, 1997).

A concepção que a escola tem sobre o conflito pode favorecer ou não a construção da autonomia moral da criança. De acordo com a teoria construtivista de Jean Piaget, há duas concepções que os educadores têm a respeito dos conflitos interpessoais, a autocrática e a democrática. Na primeira concepção, segundo Vinha e 
Tognetta (2009), as relações são pautadas pela obediência à autoridade e pela imposição de regras, favorecendo a manutenção da moral heterônoma (a obediência à regra ou ao princípio é externa) e do respeito unilateral (da criança para a autoridade, é uma via de mão única). A heteronomia faz parte do desenvolvimento moral, mas Araújo (2001) aponta que é necessário que o adulto minimize a sua autoridade, a relação de respeito unilateral e favoreça o respeito mútuo (ocorre mais nas relações entre iguais e num ambiente cooperativo). Na concepção autocrática, os autores acima apontam que o conflito é visto como algo arriscado e, portanto, precisa ser evitado, contido ou resolvido rapidamente. Ainda nesta visão, não há distinção entre as regras morais e convencionais, todas são impostas pela escola e são inegociáveis (TOGNETTA; VINHA, 2007).

Na segunda concepção, propicia-se um ambiente sociomoral cooperativo, que favorece o trabalho em grupos, as interações sociais, escolhas, responsabilidades. Para Devries e Zan (1995) e Vinha e Tognetta (2009), nessa perspectiva, haverá mais situações de conflitos, mas estes são vistos como naturais e considerados oportunidades para o desenvolvimento da autonomia moral, que é construída, principalmente, a partir de relações entre pares, ou seja, favorecendo o respeito mútuo, reconhecimento de sentimentos, trocas de perspectivas, diferente dos sermões, punições e coerção que são típicos de um ambiente autocrático. No ambiente cooperativo, há um maior respeito pelas regras morais em relação às convencionais, já que sua transgressão prejudica o outro; além disso, são construídas em conjunto com os alunos, mesmo que não possam ser negociadas, mas a sua importância é discutida (TOGNETTA; VINHA, 2007).

As intervenções frente aos conflitos, num ambiente sociomoral cooperativo, não visam apenas à resolução do mesmo, mas o processo, a maneira como a situação será enfrentada, o que também favorece o desenvolvimento cognitivo e afetivo, Como afirma Devries e Zan (1998, p.135), “[...] a atmosfera sociomoral de respeito pelas crianças é a atmosfera intelectual que apoia a construção do conhecimento e da inteligência das crianças".

Vinha e Tognetta (2009) explicitam que a maioria dos projetos políticos pedagógicos das instituições escolares tem como metas o favorecimento de relações justas, respeitosas, solidárias e trabalhos em grupos, no entanto, segundo Tognetta (2005) o que impera na prática é a concepção autocrática, não possibilitando a construção conjunta de regras e ações. 
Pesquisas apontam o quanto a instituição educativa influencia na construção moral das crianças. Os dados indicam que quanto mais o ambiente for cooperativo maior será o desenvolvimento da autonomia, sendo que se o ambiente tiver concepção autoritária, favorecerá mais a heteronomia e o respeito unilateral (ARAÚJO, 1993; VINHA, 2003; BIONDI, 2008).

Partindo da concepção dos pesquisadores estudados, o ambiente sociomoral influencia no desenvolvimento da criança e nas suas interações. Segundo Vinha (2000), o ambiente cooperativo facilita as relações pautadas no respeito mútuo e possibilita a construção dos vínculos afetivos; a autora afirma que nenhum procedimento moral terá resultado sem a construção desse vínculo. Outro fator importante a ser considerado é o apontado por Leme (2009), que considera a gestão exercida pela escola como papel fundamental nas relações interpessoais e na formação dos professores, funcionários e na tomada de decisões. Ainda segundo a autora:

É necessário que o gestor garanta um ambiente favorável à aprendizagem, organizado, com compromisso do corpo docente, onde o uso do tempo, do espaço e dos recursos está voltado prioritariamente para este fim; e também o estabelecimento de um clima de confiança, acolhimento e cuidado, onde as regras são claras e compartilhadas, em termos de direitos e responsabilidades bem definidas. (LEME, 2009, p.545).

Vinha (2000) considera que os educadores precisam estar preparados para lidar com situações de conflitos interpessoais, em especial quando se deparam com crianças consideradas "difíceis", pois precisam ter segurança e embasamento teórico que sustente o vínculo afetivo, seus procedimentos e ações.

Um importante procedimento na resolução de conflitos, segundo a autora é o uso de uma linguagem adequada por parte do educador com os alunos e suas famílias, valendo-se de uma linguagem descritiva, que consiste em descrever o que vê, ouve e sente, sem fazer julgamento de valor. Silva e Vinha (2012) relatam que a linguagem descritiva favorece relações de confiança, além de auxiliar na reflexão de suas ações, consequências dos atos e de possibilitar a percepção do ponto de vista do outro. Segundo Ginott (1973, p.57), “[...] para alcançar a mente de uma criança, o professor deve-lhe alcançar o coração [...] A criança tem direito a mensagens sadias vindas de um adulto... A linguagem determina o destino delas".

Ao fazer uso da linguagem descritiva, Vinha (2000) diz que o educador que prima pelo desenvolvimento moral de seus alunos precisará evitar mensagens de 
solução, ou seja, conduzir,, ameaçar, exigir, fazer sermão, mas descrever o conflito para a criança, levando-a a coordenar diferentes perspectivas. Segundo Faber e Mazlish (1985), na linguagem descritiva permitem-se os sentimentos, mas os atos e atitudes deverão ser sancionados.

A partir dos autores referenciados, a linguagem do educador, quando adequada, auxilia no processo de resolução de conflitos e favorece a tomada de consciência por parte da criança. Além da linguagem, outros aspectos podem contribuir ou não com a formação moral. Piaget $(1932,1994)$ estudou ainda a necessidade de sancionar de forma construtiva as ações da criança para favorecer o desenvolvimento da autonomia.

Piaget distingue dois tipos de sanções: as expiatórias e as por reciprocidade. A sanção expiatória, segundo Vinha (2000) apresenta um caráter arbitrário entre a ação e o castigo. O que a criança fez não tem relação nenhuma com o ato sancionado. O objetivo dessa sanção é fazer com que a criança que cometeu a atitude indesejável sofra e não repita mais a ação. Esse tipo de sanção é muito utilizado nas escolas autocráticas que se baseiam em procedimentos que visem o domínio e o controle por parte das figuras de autoridade e a submissão e obediência por parte dos alunos.

A sanção por reciprocidade, para Piaget (1932, 1994), caminha a par da cooperação e tem como característica a relação natural ou lógica com o ato sancionado. Ela tem como objetivo educar, fazendo com que o culpado compreenda o significado do seu ato, valorize o vínculo social e tenha o desejo de restauração. Segundo Vinha (2000, p.371), “[...] a sanção por reciprocidade auxilia na coordenação das diferentes perspectivas, permitindo à criança colocar-se no lugar do outro ou perceber o ponto de vista daquele que sofreu o efeito de sua ação".

Pesquisadores apontam que intervenções, frente aos conflitos interpessoais, pautadas na concepção construtivista, como os citados acima (sanções por reciprocidade, linguagem do educador) favorecem o desenvolvimento moral na instituição educativa. Contudo, na sociedade, como enfatiza Vinha (1999), Silveira e Wagner (2009), assim como Vinha e Tognetta (2013), existem duas instituições responsáveis pela educação do ser humano, com as quais a criança interage: a escola e a família. Ambas possuem papéis complementares e são indispensáveis para o desenvolvimento da criança; se uma delas falhar, a outra poderá obter êxito.

Para Savater (2005), Oliveira e Marinho-Araújo (2010) é na família que a criança vai aprendendo, aos poucos, diferenciar o certo do errado, de acordo com a comunidade em que vive - socialização primária. É nesta instituição que irá vivenciar o 
espaço privado, em que as relações são estáveis, diante de uma discussão entre irmão, estes não perderão o vínculo, o mesmo não ocorrendo no espaço público - escola, pois não há estabilidade nas relações; numa briga com o amigo, o vínculo poderá se romper.

Para Rego (1996), a família e a escola são as principais instituições educativas e as práticas educacionais destas têm consequências no desenvolvimento das crianças. Diante disso, as autoras (VINHA; ASSIS, 2005, p.6) colocam a questão:

Como profissionais em educação, o que a escola está fazendo para estabelecer este diálogo contínuo e reflexivo com os pais, visando, com esta troca de fato, não aparente, que haja maior afinidade nos objetivos educacionais, que se esclareça sobre alguns dos procedimentos empregados, que se modifique atitudes de ambos os lados, num espaço constante de reflexão e transformação das instituições?

Assim, Vinha e Assis (2005), Silveira e Wagner (2009), apontam o quanto a escola terceiriza os problemas para as famílias, mesmo considerando que as causas dos problemas de seus alunos tanto de aprendizagem como de comportamento sejam desta instituição, alegam que são "desestruturadas", que não tem tempo para os filhos, não colocam limites; porém, “[...] quando se transfere o problema, também se transfere o poder de resolução! Essa outra pessoa irá utilizar os procedimentos que julgar mais adequados para solucioná-lo". (VINHA; ASSIS, 2005, p.4).

Discursos sobre a importância da parceria escola-família vêm sendo proferidos pela instituição educativa (DEDESCHI; LICCIARDI, 2012). Na concepção dos educadores, parceria é quando podem contar com os pais para ajudar nas tarefas de casa, na organização de eventos, presença em reuniões periódicas. As autoras apontam esta visão de parceria como reducionista e trazem o conceito, no qual se deve pautar:

A parceria como é desenvolvida mais recentemente, num sentido bastante genérico, sempre envolve instituições e/ou indivíduos que se agregam de forma voluntária para desenvolver objetivos comuns, estabelecendo negociações coletivas compartilhadas de compromissos e responsabilidades entre si. (FOERSTE, 2005, p.70).

Polonia e Dessen (2007), Vinha e Tognetta (2013) apontam que as famílias validam o que as escolas levam até elas e suas atitudes vão sempre na direção de sanções expiatórias - ameaças, castigos físicos, sermões; ações contrárias ao desenvolvimento da autonomia. Os resultados das pesquisas dessas autoras mostram que essas ações dão resultados temporários, mas não mudam os comportamentos das crianças, em especial das consideradas "difíceis", trazendo sentimentos de angústia e 
frustração aos pais e, muitas vezes, piorando o comportamento da criança. Os pais quando são culpabilizados acabam se afastando da escola (DEDESCHI, 2011).

Silveira e Wagner (2009) ao analisar as práticas educativas utilizadas por pais e professores encontraram uma fronteira rígida entre a família e a escola, sendo que, tanto pais como as professores indicam o encaminhamento para psicólogo e a retirada da escola pelos pais quando o aluno apresenta um comportamento inadequado. Ambos indicam estas estratégias como forma de resolução de problemas com crianças difíceis. Assim como sinaliza Vinha e Assis (2005) e Dedeschi (2011), as autoras reconhecem em seu estudo que a parceria entre a família e escola mostra-se comprometida.

Os pais são responsáveis pela educação dos filhos, mas conforme as palavras de Piaget (1952, p.50), referindo-se aos direitos à educação: “[...] se todas as pessoas têm direito à educação, é evidente que os pais também possuem o direito de serem senão educados, ao menos informados e mesmo formados no tocante à melhor educação a ser proporcionada às seus filhos".

Os autores apontam a importância da escola, instituição a quem cabe formalmente à educação, oferecer formação aos pais, pois, segundo Rego (1996) e Vinha (2000), o estilo de educação praticado pela família implica na construção da autonomia dos filhos.

Uma pesquisa realizada por Turiel (apud DE LA TAILLE, 2003) apresenta três tipos de educação familiar no estabelecimento dos limites. O primeiro tipo, a educação autoritária; o segundo, a ameaça de retirada de amor e o terceiro, a elucidativa. $\mathrm{Na}$ educação autoritária, há imposição de regras por parte de uma autoridade, a qual não deve ser contestada; na educação por ameaça de retirada de amor, quando os pais ficam contrariados, mostram a criança o quanto é egoísta e pouco amorosa, chateando seus pais; já na educação elucidativa, toda vez que um limite é estabelecido é explicada a razão e a necessidade deste. Os resultados da pesquisa apontam que a educação elucidativa é a mais eficaz quando se tem como objetivo que os filhos legitimem internamente os valores e as regras morais.

Por fim, os conflitos interpessoais são inerentes às relações humanas e cabem, tanto a instituição educativa quanto à familiar, intervenções que favoreçam o desenvolvimento moral do aluno, para isso, fazem-se necessários. De acordo com Vinha (2000), educadores preparados e seguros para lidarem com as questões dentro da escola e na formação/orientação de pais. Como afirma Szymanzki (2010, p.17), em relação à família: 
Não é só como um lugar que possibilita a sobrevivência e o desenvolvimento dos seres humanos, mas como uma das instituições que assumem a tarefa educativa que lhes é outorgada pela sociedade devendo, portanto, receber apoio para o desempenho dessa função.

A partir da discussão teórica apresentada, serão realizadas algumas considerações acerca das implicações pedagógicas frente ao caso relatado, analisando, especificamente, a relação escola-família.

\section{Implicações pedagógicas}

Chamar os pais na escola, quando seus filhos se envolvem em situações de conflitos, relatar o ocorrido, dizer que a família tem que tomar providências e, por fim, levar a criança embora, são ações realizadas cotidianamente nas escolas, mas são intervenções que têm se mostrado inócuas. Segundo Vinha e Tognetta (2013), as famílias, para resolverem tais situações, utilizam com os filhos os instrumentos que conhecem, geralmente, agressões físicas, ameaças, coerções; atitudes essas que não favorecem a construção da autonomia.

Diante do caso de André, relatado nesse presente trabalho, verificamos o quanto a escola terceiriza a resolução do conflito para a família, mesmo considerando que esta seja a causadora dos problemas do filho (VINHA; ASSIS, 2005; SILVEIRA; WAGNER, 2009). A escola e a família são instituições responsáveis pela educação da criança, no entanto, é importante se atentar ao papel de cada uma, pois são complementares (espaço público e privado). A escola de André parece não considerar que os problemas referentes ao comportamento façam parte de suas funções, transferindo assim, a resolução do conflito para a família, demonstrando que, na sua visão, o educar é função desta última instituição.

$\mathrm{Na}$ família, a criança vai vivenciar as primeiras noções de certo e errado em relação ao contexto em que vive, mas é só na escola que irá vivenciar o coletivo e perceber que a manutenção das relações depende de suas ações. No caso relatado as relações na escola são pautadas pela obediência à autoridade e as regras são impostas, características de um ambiente autocrático (VINHA; TOGNETTA, 2009), o que fica evidente na fala da professora:

\footnotetext{
"André você não vai buscar nada agora, a regra da escola é que ninguém pode pegar material em outras salas, e regra é regra tem que ser cumprida, estou falando e não me interrompa".
} 
Outra questão a ser discutida, na relação escola-família, é que a primeira tem um discurso de que o problema das crianças na escola, seja de comportamento ou de aprendizagem, como no caso de André é culpa da família, (SARAIVA; WAGNER, 2013), porém, faz-se necessário considerar que o desenvolvimento da criança e a formação das características de sua personalidade se devem às experiências vivenciadas em diversos contextos, escola, amigos e não só no ambiente familiar. Como afirma Rego (1996, p.98):

Podemos inferir que mesmo as crianças provenientes de 'lares comprometidos', cujo ambiente familiar é desprovido de adequados estímulos e orientação terão condições de superar estas adversidades caso tenham a oportunidade de vivenciar, em outros contextos educativos, um modelo diferente de educação.

Desta forma fica evidente a necessidade do profissional de educação rever seus pontos de vista em relação à educação moral, pois cabe a ele, além da responsabilidade na construção da inteligência, a dos valores morais (VINHA, 1999). Quando professores (e gestores) apontam apenas as famílias como responsáveis pelas dificuldades de André e dos alunos de maneira geral, ficam numa posição que não precisam mudar suas concepções, pois as causas dos problemas são externas à instituição educativa, sendo assim, não há necessidade de repensar suas práticas e préconceitos. O que nos aponta pesquisa realizada por Silveira e Wagner (2009) “[...] a escola pareceu ter o 'controle' e delegou 'orientações' e 'encaminhamentos' as famílias, pouco se comprometendo com estas". Na situação ocorrida, em nenhum momento, a professora (coordenadora e diretora) faz uma reflexão sobre a forma que falou com o aluno (e família), não houve questionamento da importância de pegar a tesoura com o irmão, ou seja, o que foi considerado como mais importante foi à regra em si, a qual já estava pré-determinada. Porém, André em nenhum momento teve seus sentimentos reconhecidos e considerados, o que é fundamental para a construção do autorrespeito.

A escola tem o discurso de que os pais que mais necessitam não comparecem a escola, diante disso, Vinha e Assis (2005) apontam o quanto a escola precisa rever suas posturas, pois só chamam os pais quando seus filhos apresentam problema, toda vez que André apresentava comportamentos considerados inadequados pela escola, a família era chamada para ir buscá-lo e tomar providências. Os professores, muitas vezes, não têm ideia do peso de suas palavras ao falar para os pais das dificuldades de seus filhos. 
Quando a diretora e a coordenadora legitimaram a sanção expiatória, dada pela mãe a André (tirar o tablet e a TV), com certeza a mãe achou que estava tomando a decisão correta, já que sua atitude estava sendo apoiada por profissionais da educação. Pesquisas confirmam que, mesmo os pais não tendo conhecimento de como ajudar seus filhos, consideram o que é dito pelos professores e tomam providências (DEDESCHI; LICCIARDI, 2012). Também fica evidente o quanto o professor não se coloca como figura de autoridade para o aluno, já que transfere a resolução do conflito para a família, dizendo que irá chamar os pais todas as vezes que houver problema de comportamento, ficando todo o peso e responsabilidade para a família, fato esse percebido na fala da mãe ao dizer "que não aguenta mais e queria ver o que aconteceria se a escola expulsasse o filho".

Não se quer dizer com isso que os pais não devam ser informados das dificuldades dos filhos, no entanto, é diferente a família ir para a escola para contribuir com mais informações sobre a criança e dividir responsabilidades, sendo possível uma parceria entre essas duas instituições. Tem-se como ideal a parceria defendida por Foerste, (2005), em que as duas instituições tenham objetivos comuns, compartilhando compromissos e responsabilidades.

Sendo assim, André deveria arcar com as consequências de seus atos, pois quebrou mobília do patrimônio público. Ele poderia ter seus sentimentos reconhecidos, o professor poderia fazer isso utilizando-se da linguagem descritiva (FABER; MAZLISH, 1985; GINOTT, 1972), da mensagem eu, poderia ter conversado com o aluno sobre a reparação da mobília quebrada; depois a família poderia ser chamada na escola para ser informada do ocorrido, o que ficou combinado e como foi resolvido. Desta forma, a criança participaria da resolução do conflito, reconstituindo a situação, responsabilizando-se e reparando o dano, favorecendo a tomada de consciência e a construção do desenvolvimento moral, muito mais do que simplesmente mandá-la para casa e pedir para a mãe resolver.

Porém, a escola ainda parece entender como parceria, quando a família ajuda em eventos, vai às reuniões regularmente, ajuda nas tarefas do filho ou busca a criança quando se envolve em conflito, como apontado no caso de André, quando a diretora diz a mãe "toda vez que acontecer algo com o André a família será chamada para vir buscá-lo e se o comportamento não melhorar, a escola irá reduzir seu tempo de permanência nas aulas, até se comportar decentemente". 
Outro ponto que se percebe, a partir do relato do caso, é que, quando a equipe gestora terceiriza o problema, solicitando que a mãe busque o estudante e tome providências, cria conflitos na relação entre a mãe e o filho. Os pais, frequentemente, fazem uso de sanções expiatórias, como lembram Polonia e Dessen (2007) e Vinha e Tognetta (2013), ou seja, de castigos e punições que não têm qualquer relação com o ato considerado inadequado.

"Quando a mãe chegou à escola, disse para a professora, diretora e coordenadora que o filho é perseguido pela escola, e que não vê motivos para tanta confusão, que tudo que acontece na escola é culpa de seu filho, vou levá-lo embora e começou a gritar com a criança dizendo que iria tirar seu tablet por um mês e ficaria sem TV pelo mesmo tempo, que já não aguenta mais e queria ver o que aconteceria se a escola o expulsasse".

A escola também mostra seu despreparo para resolver os conflitos quando diz concordar com a mãe em tirar o objeto que a criança gosta (tablet e TV), demonstrando falta de conhecimento e habilidades para resolver a situação de maneira a favorecer a construção para autonomia.

Percebe-se, através do caso relatado, que, em geral, a escola tem a concepção de apenas chamar os pais para queixar-se e transferir problemas, diante disso, a ausência destes no ambiente escolar se intensifica cada vez mais, o que fica mais evidente quando se trata das crianças consideradas "difíceis", porque os pais já conhecem seus filhos e sabem que, ao chegar à escola, as críticas irão ocorrer, pois já passaram por isso inúmeras vezes.

Diante disso, Vinha e Assis (2005) apontam que os profissionais que atuam na escola precisam compreender a necessidade de se chamar os pais na escola, mas para compartilharem informações, ouvir as dificuldades e angústias dos mesmos a fim de que juntos dividam responsabilidades e busquem caminhos. Nas reuniões com os pais, é importante cuidar da linguagem utilizada, esta deve ser construtiva, descritiva, acessível, sem julgamentos e juízos de valor (FABER; MAZLISH, 1985; GINOTT, 1972). No caso descrito, a diretora poderia ter feito uso ao falar com a mãe da linguagem descritiva, como por exemplo, quando a mãe diz que seu filho é perseguido pela escola: "Mãe, eu entendo que você fique chateada quando chamamos você para contar sobre os ocorridos com o André e até pense que estamos perseguindo-o". Diante dessa fala a mãe poderia sentir-se acolhida e perceber que seus sentimentos foram reconhecidos, facilitando o olhar para escola como parceira e não como aquela que a 
aponta como culpada. Também poderia relatar o ocorrido de maneira descritiva: "Hoje o André saiu da sala, mesmo a professora pedindo que ficasse e sugerindo emprestar-lhe a tesoura. Acabou esbarrando com força na carteira e quebrou-a [...]".

Assim, a conversa com a família seria no sentido de informar e juntos resolverem a situação, não buscando culpados, mas caminhos, onde cada um, dentro do papel que lhe cabe, pudesse compartilhar as responsabilidades.

Educar moralmente é tarefa de toda comunidade educativa: pais, professores, gestores, sendo importante que cada instituição tenha consciência de seu papel, no entanto, cabe a instituição educativa (escola) a orientação e formação desses pais, sem terceirizar, culpar ou dizer o que é certo, mas oferecer formações que possibilitem pensar no desenvolvimento da criança (cognitivo e moral), nas relações interpessoais e nos tipos de educação familiar e suas consequências para o desenvolvimento da criança. Como apresentado anteriormente, os três tipos de educação apontados por Turiel (apud DE LA TAILLE, 2003) são: a educação autoritária, a por retirada de amor e a elucidativa.

A educação familiar de André tem características próximas à educação do tipo autoritária, em que há imposição das regras, as quais são definidas pela autoridade, fazendo uso de ameaças e castigos quando há transgressões; parece que a escola valida esse modo de educar. Esse tipo de educação tem como consequências: o conformismo, a diminuição da autoestima, o reforço da heteronomia e, muitas vezes, a rebeldia. Quando na verdade caberia orientação para a família quanto à necessidade de uma educação elucidativa, na qual o adulto não deixa de ser autoridade na relação, mas possibilita à criança participar da construção das regras, que façam escolhas e, diante dos conflitos, oportunizem o pensar e incentivem a busca de reparação e de uma melhor forma de agir respeitando a si e ao outro. Como consequência, existiria uma maior legitimação interna das regras e dos valores morais, estima positiva de si, maior autocontrole e um caminho para a autonomia.

Essa formação dos pais, para o favorecimento da autonomia moral dos filhos, poderá ocorrer no dia a dia, na parceria que se estabelece e em encontros formais de estudos e reflexões. Para isso, deve-se ressaltar que a escola precisa se conscientizar da necessidade de uma gestão democrática e de um ambiente sociomoral cooperativo, que favoreça o desenvolvimento moral, cognitivo e afetivo do aluno, incluindo, com isso, a família como sua parceira, dividindo responsabilidades e assumindo o papel que lhes cabe. 


\section{Considerações Finais}

Esse artigo teve como objetivo compreender e analisar as intervenções realizadas pela escola, no que diz respeito ao desenvolvimento moral de uma criança considerada "difícil”, especificamente discutindo a relação entre a escola e a família.

A partir da perspectiva da teoria construtivista piagetiana é considerado como papel, também da escola, o desenvolvimento moral dos alunos, o que é favorecido quando a escola tem a concepção democrática, propiciando, assim, um ambiente sociomoral cooperativo, o qual prima pelo respeito mútuo, pelas interações sociais, dê oportunidade de escolhas e consequentemente de assumir responsabilidades, assim como, a parceria cooperativa entre a escola e a família.

Quanto à relação família-escola, percebe-se claramente o quanto a escola terceiriza a resolução do conflito para a família, mesmo considerando que esta seja o motivo das dificuldades da criança. Responsabiliza-a por resolver conflitos que ocorrem no interior do espaço escolar, demonstrando que não se coloca nos problemas; assim, não questionam suas concepções e práticas.

A partir da análise do caso de André, conclui-se que a criança convive em um ambiente escolar autocrático, que não reflete sobre as regras e os sentimentos dos alunos, acredita em sanções expiatórias como forma de educação dos mesmos, e, ainda, culpabiliza e transfere a solução dos conflitos para a família; esta, por despreparo, endossa um estilo de educação autoritária.

Todavia, vê-se a necessidade de repensar a concepção da escola, criando um espaço que favoreça o desenvolvimento moral e cognitivo dos alunos. Neste espaço, faz-se importante o envolvimento de toda a comunidade educativa (professores, gestores, funcionários e família), pois todos são responsáveis pelo desenvolvimento moral da criança, dentro do papel que cabe a cada um.

No entanto, isso é possível dentro de um espaço democrático e a escola, sendo a instituição formal responsável pela educação, possa dar o primeiro passo para repensar sua prática, suas concepções e relação existente com a família. Tornando-se parceiros, compartilhando responsabilidades e favorecendo a construção de seres humanos mais respeitosos consigo e com o outro. Para isso faz-se necessário à formação dos educadores a fim de estabelecer uma parceria cooperativa. 


\section{MORAL DEVELOPMENT OF A “HARD CHILD”: FOCUS ON SCHOOL- FAMILY RELATIONSHIP}

ABSTRACT: From a scholar case report, this paper intended to comprehend and analyze school's interventions in the moral development of a hard child, especially relating to school-family. From that case analysis, it was concluded that the child lives at a scholar autocratic environment with no rules thinking, with no concern about student's emotions, which uses expiatory sanctions for educating. It was also concluded that exists a difficulty in establishing a partnership between school and family because conflicts were delegated from the first one to the second one.

KEYWORDS: Interpersonal conflicts. Moral development. School-family partnership.

\section{REFERÊNCIAS}

ARAÚJO, A. F. O ambiente escolar cooperativo e a construção do juízo moral infantil: sete anos de estudo longitudinal. Revista Online da Biblioteca Prof. Joel Martins, Campinas, v.2, n.2, p.1-11, fev. 2001.

Um estudo da relação entre o ambiente cooperativo e o julgamento moral na criança. 1993. 208f. Dissertação (Mestrado em Educação) - Faculdade de Educação, Universidade Estadual de Campinas, Campinas, 1993.

BBC. Pesquisa põe Brasil em topo de ranking de violência contra professores. G1 Globo, [online], 28 ago. 2014. Disponível em:

<http://g1.globo.com/educacao/noticia/2014/08/pesquisa-poe-brasil-em-topo-deranking-de-violencia-contra-professores.html>. Acesso em: 30 set. 2014.

BIONDI, R. Sistema de Avaliação da Educação Básica - SAEB. Instituto Nacional de Estudos e Pesquisas Educacionais Anísio Teixeira (INEP)/Ministério da Educação e do Desporto. Brasília: MEC/SEF, 2008. Disponível em:

<http://www.inep.gov.br/basica/saeb>. Acesso em: 12 mar. 2008.

DEDESCHI, S. C. C. Bilhetes reais e/ou virtuais: uma análise construtivista da comunicação entre escola e família. 2011. 278f. Dissertação (Mestrado em Educação) Faculdade de Educação, Universidade Estadual de Campinas, Campinas, 2011.

.; LICCIARDI, L. De quem é a tarefa de educar moralmente? A comunidade educativa na gerência da violência na escola. In: TOGNETTA, L. R. P.; VINHA, T. P. (Org.). É possível superar a violência na escola? Construindo caminhos pela formação moral. São Paulo: Editora do Brasil, 2012. p.139-157.

DE LA TAILLE, Y. Limites: três dimensões educacionais. São Paulo: Ática, 2003.

DEVRIES, R.; ZAN, B. Creating a constructivist classroom atmosphere. Young Children, [S.1.], v.51, n.1, p.4-13, nov. 1995. 
Uma abordagem construtivista do papel da atmosfera sociomoral na promoção do desenvolvimento das crianças. In: FOSNOT, C. T. Construtivismo: teoria, perspectivas e práticas pedagógicas. Porto Alegre: ARTMED, 1998. p.123-140.

FABER, A; MAZLISH, E. Pais liberados, filhos liberados. São Paulo: Ibrasa, 1985.

FOERSTE, E. Parceria na formação de professores. São Paulo: Cortez, 2005.

GINOTT, H. G. O professor e a criança. Tradução de Helena Boscoli. Rio de Janeiro: Edições Bloch, 1973.

Pais e filhos: novas soluções para velhos problemas. Tradução de Flavio Costa. Rio de Janeiro: Edições Bloch, 1972.

LEME, M. I. S. A gestão da violência escolar. Revista Diálogo Educacional (PUCPR. Impresso), Curitiba, v.9, n.28, p.541-555, 2009.

OLIVERA, C. B. E; MARINHO-ARAÚJO, C. M. A relação família-escola; intersecções e desafios. Estudos de Psicologia, Campinas, v.27, n.1, p.99-108, jan./mar. 2010.

PIAGET, J. O juízo moral da criança. São Paulo: Summus, 1994.

O julgamento moral da criança. São Paulo: Mestre Jou, 1932.

. The origins of intelligence in children. New York: International Universities Press, 1952.

POLONIA, A. C.; DESSEN, M. A. A família e a escola como contextos de desenvolvimento humano. Paidéia, Ribeirão Preto, v.17, n.36, p.21-32, 2007.

REGO, T. C. R. A indisciplina e o processo educativo: uma análise na perspectiva Vygotskyana. In: AQUINO, J. G. (Org.). Indisciplina na escola: alternativas teóricas e práticas. São Paulo: Summus, 1996. p.101-127.

SÃO PAULO. (Estado). APEOESP. Sindicato dos Professores do Ensino Oficial do Estado de São Paulo. Caderno violência nas escolas - análise da pesquisa. São Paulo: CEPES/APEOESP, 2013. Disponível em:

<http://www.apeoesp.org.br/publicacoes/observatorio-da-violencia/caderno-violencianas-escolas-analise-da-pesquisa $>$. Acesso em: 05 out. 2014.

SAVATER, F. O eclipse da família. In: SAVATER, F. (Org.). O valor de educar. São Paulo: Planeta do Brasil, 2005. p.57-87.

SILVA, L. M.; VINHA, T. Os conflitos interpessoais na infância e o ambiente escolar. In: GARMS, G. M. Z.; GUIMARÃES, S. R. A. (Org.). Temas e dilemas pedagógicos da educação infantil: desafios e caminhos. Campinas: Mercado das Letras, 2012. p.173-212. 
SILVEIRA, L. M. O. B; WAGNER, A. Relação família-escola: práticas educativas utilizadas por pais e professores. Associação Brasileira de Psicologia Escolar e Educacional (ABRAPEE), Maringá, v.13, n.2, p.283-291, jul./dez. 2009.

SARAIVA, L. A.; WAGNER, A. A relação família-escola sob a ótica de professores e pais de crianças que frequentam o ensino fundamental. Ensaio: avaliação e políticas públicas em educação, Rio de Janeiro, v.21, n.81, p.739-772, out./dez. 2013.

SZYMANSKI, H. Educação e família. In: SZYMANSKI, H. A relação família/escola: desafios e perspectivas. 2.ed. Brasília: Liber Livro, 2010. p.17-46.

VINHA, T. P. O educador e a moralidade infantil: uma visão construtivista. Campinas: Mercado de Letras, 2000.

Os conflitos interpessoais na relação educativa. 2003. 427f. Tese (Doutorado em Educação) - Universidade Estadual de Campinas, Campinas, 2003.

Valores morais em construção. Revista AMAE-Educando, Belo Horizonte, n.285, p.6-12, 1999.

; ASSIS, O. Z. M. Compartilhar ou transferir as responsabilidades? Considerações sobre a relação entre a escola e a família. In: ENCONTRO NACIONAL DE PROFESSORES DO PROEPRE: "EDUCAÇÃO E CIDADANIA", 2005. Anais... Campinas: Ed. da UNICAMP, 2005, p.15-32.

VINHA, T. P.; TOGNETTA, L. R. P. A comunicação entre escola e família por meio dos bilhetes ou notificações eletrônicas. In: III Congresso Internacional de convivência escolar, 2013, Almeria/Espanha, v.1, p.349, 2013.

Construindo a autonomia moral na escola: os conflitos interpessoais e a aprendizagem dos valores. Revista Diálogo Educacional, Curitiba, v.9, n.28, p.525540, set./dez. 2009.

TRAIN, A. Ajudando a criança agressiva. Campinas: Papirus, 1997.

TOGNETTA, L. R. P. O mapa do problema escolar: quando a cidadania parece não ser possível. In: ENCONTRO NACIONAL DE PROFESSORES DO PROEPRE: "EDUCAÇÃO E CIDADANIA", 2005. Anais... Campinas: Ed. da UNICAMP, 2005, p.109-120.

TOGNETTA, L. P.; VINHA T. P. Quando a escola é democrática: um olhar sobre a prática de regras e assembleias na escola. Campinas: Mercado de Letras, 2007. 